\title{
Status of Insecticide Resistance of Malaria Vector Anopheles stephensi towards Insecticides in Alwar District of Rajasthan, India
}

\author{
Nitesh Kumar Sharma ${ }^{1,2}$, Mohammad Irfan Ali' ${ }^{2}$ Sarmad Moin ${ }^{2}$ \\ ${ }^{1}$ Assistant Professor, Zoology, SBP Government College, Dungarpur, Rajasthan, India. \\ ${ }^{2}$ School of Applied Sciences, Suresh Gyan Vihar University, Jaipur, India. \\ DOI: https://doi.org/10.24321/0019.5138.202109
}

\section{I $\quad \mathbf{N} \quad \mathbf{F} \quad \mathbf{O}$}

\section{Corresponding Author:}

Sarmad Moin, School of Applied Sciences, Suresh

Gyan Vihar University, Jaipur, India.

E-mail Id:

moinsarmad@gmail.com

Orcid Id:

https://orcid.org/0000-0002-3418-5678

How to cite this article:

Sharma NK, Ali MI, Moin S. Status of Insecticide Resistance of Malaria Vector Anopheles stephensi towards Insecticides in Alwar District of Rajasthan, India. J Commun Dis 2021; 53(1): 58-61.

Date of Submission: 2020-11-22

Date of Acceptance: 2021-01-22

\section{$\begin{array}{llllllll}\mathbf{A} & \mathbf{B} & \mathbf{S} & \mathbf{T} & \mathbf{R} & \mathbf{A} & \mathbf{C} & \mathbf{T}\end{array}$}

Pyrethroids have been developed as a powerful insecticide that is widely used for space spray and residual indoor spraying, with impregnated nets included in the vector control programme. Insecticide resistance reduces the effectiveness of pesticides. Therefore, the vector susceptibility condition of the Anopheles stephensi is monitored in order to select the active ones. The current study is being conducted in a malariaridden area in various parts of the Alwar region of Rajasthan, India, against the malaria vector An. stephensi. The Susceptibility study was conducted by the WHO standardized method using the diagnostic doses of DDT, Alpha-cypermethrin and Deltamethrin. An. stephensi showed intermediate resistance to DDT from all over the study while susceptible to Alpha-cypermethrin and Deltamethrin.

Keywords: Anopheles, Insecticide Resistance, Mosquito Control, DDT, Alpha-cypermethrin, Deltamethrin

\section{Introduction}

Malaria is a global health problem and a life-threatening disease that accounts for $95 \%$ of the population at risk of infection transmitted by human parasites i.e. the female Anopheles mosquito. In 2018, there are an estimated 228 million cases of malaria worldwide. ${ }^{1}$ Globally, $53 \%$ of the plasmodium vivax burden is in the WHO South-East Asia region, mostly in India (47\%). Globally, approximately $85 \%$ of deaths related to malaria by 2018 are reported in 20 nations including the African and Indian regions. About $85 \%$ of all malaria cases worldwide were in 19 countries including India and 18 African countries. More than $85 \%$ of $P$. vivax malaria cases estimated in 2018 occur in only six countries, with India accounting for $47 \%$ of all $P$. vivax cases worldwide. ${ }^{2}$

Numerous species of Anopheles are accountable for spreading malaria. The Anopheles stephensi Liston is the most prevalent species for transmitting malaria discovered in the arid and semi-arid zones of Rajasthan. Anopheles stephensi (An. stephensi) is a type of sub-tropical species that spreads throughout the Middle East and South Asia and is a major vector in urban areas of India that accounting for about $12 \%$ of malaria cases annually. This species is a major transmitter of malaria, an important vector in the arid regions of Rajasthan where it has a unique breeding ground for underground water tanks spread across villages and urban areas. ${ }^{3}$

To prevent malaria, the WHO recommends vector control (i.e. reducing the chances of mosquito bites) or preventing chemotherapy (i.e. providing antibiotics) in certain groups of people (i.e. pregnant women, children and other high-risk groups) or certain conditions (e.g. complicated emergencies and terminations). Primary interventions like InsecticideTreated Nets (ITNs) and Indoor Residual Spraying (IRS) are suggested by the WHO to prevent mosquito stings during 
sleeping. In certain specific circumstances, ITNs and IRS may be added to larval resources management or other environmental modifications. ${ }^{2}$

The Insecticides used to fight malaria parasites most of them were Organochlorines (OCs), DDT is the only pesticide reported to be used to control vector; Organophosphates (OPs) such as fenitrothion, temephos and malathion; carbamate (C) such as propoxur and bandocarb; Pyrethroids (PYs) such as alpha-cypermethrin, cyfluthrin, bifenthrin, cyphenothrin, cypermethrin, etofenprox, deltamethrin, permethrin and lambda-cyhalothrin; Insect Growth Regulators (IGRs) such as diflubenzuron, novaluron, methoprene, and pyriproxyfen. ${ }^{3}$ Synthetic pyrethroids are widely used for residual indoor sprays, space sprays and impregnated bed nets. This is very effective, if used properly, but resistance to these chemicals reduces its effect. ${ }^{5}$

However, the continued use of targeted insecticides has led to the development of resistance to many malaria vectors worldwide. In India several species of anopheline have been resistant to insecticides. An. culicifacies, which is the main vector of malaria in India, which accounts for $60-70 \%$ of malaria cases, has been shown to be resistant to malathion and DDT in India. ${ }^{4}$

A current study was conducted to determine the susceptibility status of An. stephensi adults and caterpillar stages in WHO recommended insecticides. The data generated will ensure that the insecticide pattern required in these areas avoids the increasing use of insecticide that could threaten the sustainability of the vector control strategy leading to increased insecticide resistance. Hence, observing the insecticide susceptibility state against malaria transmitters An. Stephensi in the Alwar district of Rajasthan will generate data that accommodate the prospective pest control program and approaches directed to fighting malaria.

\section{Material and Method}

\section{Test Insects}

Mosquitoes were collected at night between 10:00 PM and
12:00 PM by sucking tube method and kept in cages. An. stephensi mosquitoes are fed with a $10 \%$ glucose solution ad libitum released using a cotton wick. ${ }^{6}$

\section{Insecticides}

The insecticide susceptibility tests were performed on three insecticides called DDT, Alpha-cypermethrin and Deltamethrin, used for the indoor residual spray in malaria control program. According to WHO recommend diagnostic doses, insecticide-impregnated papers of DDT (4\%), alphacypermethrin (0.05\%), Deltamethrin (0.05\%) were using for insecticide susceptibility tests on the collected malaria vector species An. stephensi.

\section{Insecticide Susceptibility Tests}

The test for susceptibility of insecticides was done according to the WHO standard procedure between April/ May 2019. An. Stephensi has been exposed to insecticide-impregnated papers for an hour. A standard test to determine insecticide susceptibility in An. Stephensi mosquito was made by mosquitoes caught in the field using diagnostic doses of insecticide. ${ }^{7}$ The WHO standard was adopted to determine the susceptibility state of An. Stephensi, if mortality is found more than $98 \%$ the vector consider to be susceptible, if mortality is observed less than $80 \%$ the vector consider to be resistant, and if mortality is found between $80-98 \%$ the vector consider intermediate resistant. The deaths of test subjects were corrected using Abbott's formula if the death in control was considered $5-20 \%{ }^{8}$

\section{Result and Discussion}

Susceptibility status of the malaria vectors collected from various towns of Alwar in reference to various insecticides shown in Table 1. Results of Insecticide Susceptibility Tests shows that DDT is intermediate resistant in all four towns of Alwar district, while Alpha-cypermethrin \& Deltamethrin are susceptible in all four towns of Alwar district. The above study will help the concerned departments and agencies in deciding malaria vector control strategy.

Table I.Bioassay of DDT, Alpha-cypermethrin and Deltamethrin to An. stephensi

\begin{tabular}{|c|c|c|c|c|c|c|c|c|c|c|}
\hline \multirow[t]{2}{*}{$\begin{array}{l}\text { S. } \\
\text { No. }\end{array}$} & \multirow[t]{2}{*}{ Town } & \multirow[t]{2}{*}{$\begin{array}{l}\text { Insecticide (\% } \\
\text { conc. tested) }\end{array}$} & \multicolumn{2}{|c|}{$\begin{array}{c}\text { No. of } \\
\text { mosquitoes } \\
\text { exposed }\end{array}$} & \multicolumn{2}{|c|}{$\begin{array}{c}\text { No. of } \\
\text { mosquitoes } \\
\text { dead }\end{array}$} & \multicolumn{2}{|c|}{ Mortality (\%) } & \multirow{2}{*}{$\begin{array}{c}\text { Corrected } \\
\text { mortality } \\
(\%)\end{array}$} & \multirow[t]{2}{*}{$\begin{array}{c}\text { Susceptibility } \\
\text { status }\end{array}$} \\
\hline & & & Test & Control & Test & Control & Test & Control & & \\
\hline 1. & Mandawar & DDT (4\%) & 95 & 55 & 84 & 5 & 88.42 & 9.09 & $87.26 \%$ & $\begin{array}{c}\text { Intermediate } \\
\text { Resistant }\end{array}$ \\
\hline 2. & & $\begin{array}{c}\text { Alpha- } \\
\text { cypermethrin } \\
(0.05) \\
\end{array}$ & 97 & 40 & 97 & 3 & 100 & 7.5 & $100 \%$ & Susceptible \\
\hline 3. & & $\begin{array}{c}\text { Deltamethrin } \\
\quad(0.05)\end{array}$ & 103 & 45 & 103 & 2 & 100 & 4.44 & $100 \%$ & Susceptible \\
\hline
\end{tabular}




\begin{tabular}{|c|c|c|c|c|c|c|c|c|c|c|}
\hline 4. & Rajgarh & DDT (4\%) & 105 & 53 & 92 & 3 & 87.61 & 5.66 & $86.87 \%$ & $\begin{array}{l}\text { Intermediate } \\
\text { Resistant }\end{array}$ \\
\hline 5. & & $\begin{array}{c}\text { Alpha- } \\
\text { cypermethrin } \\
(0.05) \\
\end{array}$ & 98 & 62 & 98 & 4 & 100 & 6.45 & $100 \%$ & Susceptible \\
\hline 6. & & $\begin{array}{c}\text { Deltamethrin } \\
(0.05)\end{array}$ & 99 & 52 & 99 & 2 & 100 & 3.84 & $100 \%$ & Susceptible \\
\hline 7. & Ramgarh & DDT (4\%) & 83 & 42 & 72 & 3 & 86.74 & 7.14 & $85.72 \%$ & $\begin{array}{l}\text { Intermediate } \\
\text { Resistant }\end{array}$ \\
\hline 8. & & $\begin{array}{c}\text { Alpha- } \\
\text { cypermethrin } \\
(0.05)\end{array}$ & 97 & 45 & 97 & 4 & 100 & 8.88 & $100 \%$ & Susceptible \\
\hline 9. & & $\begin{array}{c}\text { Deltamethrin } \\
(0.05)\end{array}$ & 102 & 54 & 102 & 3 & 100 & 5.55 & $100 \%$ & Susceptible \\
\hline 10. & Thanagazi & DDT (4\%) & 105 & 52 & 95 & 3 & 90.47 & 5.76 & $89.89 \%$ & $\begin{array}{c}\text { Intermediate } \\
\text { Resistant }\end{array}$ \\
\hline 11. & & $\begin{array}{c}\text { Alpha- } \\
\text { cypermethrin } \\
(0.05) \\
\end{array}$ & 95 & 46 & 95 & 2 & 100 & 4.34 & $100 \%$ & Susceptible \\
\hline 12. & & $\begin{array}{l}\text { Deltamethrin } \\
(0.05)\end{array}$ & 97 & 47 & 97 & 3 & 100 & 6.38 & $100 \%$ & Susceptible \\
\hline
\end{tabular}

An. stephensi was intermediate resistant to DDT by $87.26 \%$ in Mandawar, whereas $86.87 \%$ in Rajgarh, $85.72 \%$ in Ramgarh and $89.89 \%$ in Thanagazi, whereas it was susceptible to Alpha-cypermethrin and Deltamethrin by $100 \%$, in Mandawar, Rajgarh, Ramgarh and Thanagazi, town.

In the aforementioned study, intermediate resistance against DDT was observed in An. Stephensi, relevant study to analyse the susceptible status of An. Stephensi carried out in the Jodhpur, Barmer, and Jaisalmer region of the Thar desert, Rajasthan perceived resistance against DDT, and susceptible against Deltamethrin. ${ }^{9}$ Another study was conducted in Goa to check the susceptibility status of $A n$. stephensi were also observed resistant against DDT and the triple resistance perceived against DDT, dieldrin, and malathion. ${ }^{10}$

Insecticide susceptibility tests were conducted on An. stephensi against the diagnostic doses of insecticides DDT in District Bikaner (Rajasthan) and An. stephensi found resistant to DDT. ${ }^{11}$ In another investigation conducted in Sri Lanka to evaluate susceptibility status in An. subpictus perceived high resistance against DDT. ${ }^{12}$ Bioassay shows that An. stephensi collected from various locations of Arid and Semi-Arid Zone of India during 2005-07 were susceptible to DDT. ${ }^{13}$

The susceptibility status was assessed at diagnostic doses of DDT, deltamethrin and alphacypermethrin using the standard WHO method and observed tolerant to deltamethrin by $86.1 \%$, and alphacypermethrin $90.6 \%$, whereas it was susceptible to DDT by $98.1 \% \cdot{ }^{14} \mathrm{An}$. stephensi were resistant to deltamethrin insecticides with mortality rates $67 \%$ and resistance to DDT was detected with mortality rates of $32 \%$ in study conducted in eastern Ethiopia. ${ }^{15}$

An. stephensi was highly susceptible to deltamethrin in Rajasthan and Gujarat, and susceptible to lambdacyhalothrin in Karnataka state. ${ }^{16}$ An. stephensi, are resistant to multiple insecticides although resistance varies dramatically between populations, apparently depending on the history of insecticide use and selection. ${ }^{17}$

Widespread resistance to vectors was one of the factors contributing to the ineffectiveness of DDT in India. ${ }^{18}$ Stockholm's conference on the sustainable use of natural waste can be freed from the production and public health use of DDT in indoor application to control vector-borne diseases, mainly due to the lack of more efficient and effective alternatives. The WHO has suggested that there be no change in its current recommendations for the safety of DDT for vector disease control, with continuous monitoring of insecticide resistance for the selection of insecticide and the optimum use of resistance management strategies. ${ }^{19}$

\section{Conclusion}

The development of insecticide resistance could be a major impediment to the national malaria control program due to the unavailability of alternative, safer and less expensive insecticides. From a safety and efficiency perspective, pyrethroids are the best insecticides ever used for 
public health use. It is therefore important to use this very important group of pesticides wisely and cautiously, constantly monitoring the state of pesticide resistance in vectors to find an effective vector control program. In the current study intermediate resistant of An. stephensi to DDT is important findings as this has never been studied in the Alwar region of Rajasthan, and Alpha-cypermethrin and Deltamethrin are most susceptible to this insecticide. The study looks at the selection and rotation of the appropriate pesticide molecule for better vector control program. There is a need for constant monitoring of insecticides in order to develop effective vector control strategies such as modifying insecticides, applying integrating biological and ecological approaches.

\section{Acknowledgment}

Authors are thankful to Board of Management \& Academic Council of Suresh Gyan Vihar University for providing facility throughout the research work.

\section{Sources of Funding: None \\ Conflict of Interest: None \\ References}

1. World Health Organization. Key facts on malaria. Available from: https://www.who.int/news-room/ fact-sheets/detail/malaria. 2020.

2. World Health Organization. World malaria report. Available from: https://apps.who.int/iris/rest/ bitstreams/1262394/retrieve. 2019.

3. World Health Organization. Pesticides and their application for the control of vectors and pests of public health importance. 2006.

4. Dash AP, Raghavendra K, Pillai MKK. Combating Resistance to Insecticides in Malaria Control- Gains Made in India. Bayer Environmental Science Journal 2006; 18: 30-37.

5. N'Guessan R, Corbel V, Akogbéto $M$ et al. Reduced efficacy of insecticide-treated nets and indoor residual spraying for malaria control in pyrethroid resistance area, Benin. Emerging Infectious Diseases 2007; 13(2): 199.

6. OMS. Manual on practical entomology in Malaria. Part. II. 1975.

7. World Health Organization. Test procedures for insecticide resistance monitoring in malaria vector mosquitoes. 2016.

8. Abbott WS. A method of computing the effectiveness of an insecticide. J Ecol Entomol 1925; 18: 265-467.

9. Singh KV, Bansal SK. Mapping of insecticide resistance in vectors of malaria in Rajasthan. Annual Report, 2007.

10. Thavaselvam D, Kumar A, Sumodan PK. Insecticide Susceptibility Status of Anopheles stephensi, Culex quinquefasciatus and Aedes aegypti in Panaji, Goa.
Malaria Research Centre 1993; 30: 75-79.

11. Bansal SK, Singh KV. Insecticide susceptibility status of some anophelines in district Bikaner, Rajasthan. Indian Journal of Malariology 1996; 33(1): 1-6.

12. Perera MDB, Hemingway J, Karunaratne SP. Multiple insecticide resistance mechanisms involving metabolic changes and insensitive target sites selected in anopheline vectors of malaria in Sri Lanka. Malaria Journal 2008; 7(1): 168.

13. Tikar SN, Mendki MJ, Sharma AK et al. Resistance status of the malaria vector mosquitoes, Anopheles stephensi and Anopheles subpictus towards adulticides and larvicides in arid and semi-arid areas of India. Journal of Insect Science 2011; 11(1): 85.

14. Tiwari S, Ghosh SK, Ojha VP et al. Reduced susceptibility to selected synthetic pyrethroids in urban malaria vector Anopheles stephensi: a case study in Mangalore city, South India. Malaria Journal 2010; 9(1): 1-5.

15. Yared S, Gebressielasie A, Damodaran Let al. Insecticide resistance in Anopheles stephensi in Somali Region, eastern Ethiopia. Malaria Journal 2020; 19: 1-7.

16. Bhatt RM, Sharma SN, Barik TK et al. Status of insecticide resistance in malaria vector, Anopheles culicifacies in Chhattisgarh state, India. J Vector Borne Dis 2012; 49: 36-8.

17. Chang X, Zhong D, Fang Q et al. Multiple resistances and complex mechanisms of Anopheles sinensis mosquito: a major obstacle to mosquito-borne diseases control and elimination in China. PLoS Negl Trop Dis 2014; 8: e2889.

18. Sharma RS, Sharma SN, Kumar A. Susceptibility status of Japanese encephalitis vectors in Kurnool and Mehboobnagar districts of Andhra Pradesh, India. The Journal of Communicable Diseases 2003; 35(2): 118.

19. World Health Organization. The Use of DDT in Malaria Vector Control WHO position statement. Global Malaria Program, 2007. 